DOI 10. 18307/2017. 0126

(C) 2017 by Journal of Lake Sciences

\title{
泸沽湖近代沉积环境时空变化特征及原因分析”
}

\author{
林 琪 $^{1,2}$, 刘恩峰 ${ }^{1 * *}$, 张恩楼 $^{1}$, 沈 吉 $^{1}$, 袁和忠 $^{3}$,王 荣 ${ }^{1}$ \\ (1:中国科学院南京地理与湖泊研究所湖泊与环境国家重点实验室,南京 210008) \\ (2: 中国科学院大学,北京 100049) \\ (3: 南京信息工程大学环境科学与工程学院,南京 210044)
}

\begin{abstract}
摘 要: 通过对沪沽湖沉积岩芯粒度、磁化率 $\left(X_{\text {If }}\right)$ 、化学蚀变指数 (CIA) 等沉积指标的分析, 结合 ${ }^{210} \mathrm{~Pb}$ 和 ${ }^{137} \mathrm{Cs}$ 定年结果 以及区域降水和人类活动等资料,研究了近 150 年来沾沽湖沉积环境的时空变化特征与主要影响因素. 沾沽湖沉积物粒 度组成以黏土与细粉砂为主 $\left(>80 \%\right.$ ), 细颗粒组分 (如黏土) 含量与 $X_{\text {If }}$ CIA 之间具有显著相关性. 各岩芯沉积指标垂向

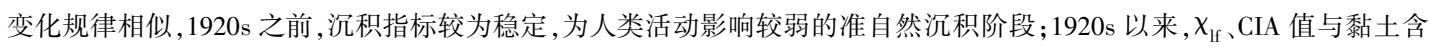
量逐渐升高, 反映了风化与成壤作用较强的细颗粒表土物质侵蚀开始加强, 可能与流域农业发展及森林砍伐等人类活动 影响有关; 约 1970 年以来, $\chi_{\mathrm{If}}$ 、CIA 值与黏土含量进一步升高, 指示了流域内表土侵蚀与上述人类活动影响的进一步增 强, 与文献记录的 $1970 \mathrm{~s}-1980 \mathrm{~s}$ 两次大规模的森林砍伐吻合; 约 2002 年以来, $X_{\text {If }}$ CIA 值与黏土含量降低, 反映了表土侵 蚀减弱, 与近年来流域植被逐渐恢复及降水减少有关. 与器测资料对比研究表明, 降水等气候因素对近代泸沽湖沉积环 境演变的影响相对较弱. 空间上, 各沉积指标表现出一定的异质性. 黏土含量在南部和北部湖区两侧靠近洪积扇及冲积 平原的湖区沉积物中较高; 近 50 年以来, 各沉积岩芯所反映的平均沉积通量为 $0.020 \sim 0.043 \mathrm{~g} /\left(\mathrm{cm}^{2} \cdot \mathrm{a}\right)$, 南部湖区高于 北部湖区, 主要受人湖水系分布及流域南部地区高强度人类活动导致的土壤侵蚀的影响.
\end{abstract}

关键词: 泸沽湖;沉积特征; 时空变化; 人类活动

\section{Temporal and spatial variations in sedimentary characteristics of Lake Lugu during the last hundred years and the influence factors analysis}

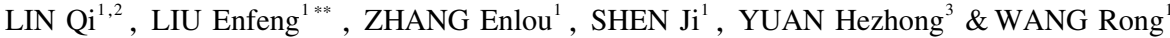

(1: State Key Laboratory of Lake Science and Environment, Nanjing Institute of Geography and Limnology, Chinese Academy of Sciences, Nanjing 210008, P.R. China)

(2: University of Chinese Academy of Sciences, Beijing 100049, P.R.China)

(3: School of Environmental Science and Engineering, Nanjing University of Information Science and Technology, Nanjing 210044, P.R.China)

\begin{abstract}
Twelve short sediment cores were collected from Lake Lugu to analyze the particle size composition, magnetic susceptibility $\left(X_{\mathrm{lf}}\right)$, metal content and chemical index of alteration (CIA) in this study. Referencing to the ${ }^{210} \mathrm{~Pb}$ and ${ }^{137} \mathrm{Cs}$ dating results, natural factor such as precipitation on the sedimentary characteristics, and human activity records such as agricultural expansion and deforestation, the temporal and spatial variations in sedimentary characteristics of Lake Lugu in recent 150 years and were discussed. The results indicated that the sediments of Lake Lugu were mainly ( $>80 \%$ ) composed of clay and fine silt. The fine fractions ( such as clay) showed typical positive correlations with $\chi_{\text {If }}$ and CIA. The sedimentary proxies showed similar vertical changes in the cores from different lake areas. Before 1920s, $X_{\text {If }}$ and CIA remained low values and the grain size compositions were stable, suggesting weak human disturbance and stable particle input from the catchment. The clay content, $\chi_{\mathrm{lf}}$ and CIA increased gradually since 1920s, which were more remarkable change since $c a .1970$, indicating enhanced erosion of well-weathered and fine-grained
\end{abstract}

* 科技部基础性工作专项(2014FY110400)、国家重点基础研究发展计划项目(2012CB956104) 和国家自然科学基金 项目 (41271214) 联合资助. 2016-03-23 收稿;2016-05-05 收修改稿. 林琪 (1990 ), 男, 硕士研究生; E-mail: linqiww0523@163.com.

** 通信作者;E-mail: efliu@ niglas.ac.cn. 
topsoil probably relating to intensive agricultural development and deforestation in Lake Lugu Catchment. The $\chi_{\text {If }}$ and CIA tended to decreasing and median grain size increased since around 2002, which suggested decreasing topsoil erosion attributing to the implement of environmental protection measures such as vegetation recovery in the catchment. Study between the sedimentary proxies and instrumental data showed that climate factors such as precipitation had a weaker effect on the sedimentary evolution of Lake Lugu when compared to human perturbation. Spatially, the sedimentary proxies showed obvious heterogeneity. There was higher clay content in the surface sediments in north and south lake areas where they were near the pluvial-alluvial plains. The mean mass accumulation rates were $0.020-0.043 \mathrm{~g} /\left(\mathrm{cm}^{2} \cdot \mathrm{a}\right)$ since 1964, which showed higher values in the south Lake Lugu than in the north Lake Lugu. The high accumulation rate in the south lake should be ascribed to a fact that are influenced by inflow and outflow rivers and the strong soil erosion from the south catchment caused by intensive human activities.

Keywords: Lake Lugu; deposition features; temporal and spatial variations; human activities

近年来, 随着人类活动影响的不断增强, 全球湖泊环境问题日益突出, 主要表现在湖泊淤积、富营养化 和污染等方面 ${ }^{[-3]}$, 由此导致湖泊生态服务功能显著降低 ${ }^{[4]}$. 湖泊生态环境变化除了受到氮磷、有机物与重 金属等污染物的影响之外, 人类活动与气候变化导致的土壤侵蚀以及人湖颗粒物来源与组成的改变, 对水 体透明度与沉积物质地具有较大影响, 进而影响到湖泊生物群落的演替和生态环境演化 ${ }^{[4-5]}$. 开展湖泊沉积 物来源与沉积环境演化重建研究, 区分人与自然要素的影响, 对科学认识湖泊环境演化的规律、有效开展环 境保护具有重要意义.

目前, 在湖泊沉积环境演化重建方面主要采用单一钻孔或者少数钻孔 ${ }^{[6-8]}$. 然而, 研究表明, 受到湖底地 形、湖流、径流和流域人类活动强度等因素的影响, 同一湖泊不同湖区沉积指标变化趋势与数值可能存在差 异, 在沉积通量、碳埋藏量与污染物累积量等定量方面采用单一岩芯存在较大误差. Rippey 等 $^{[8]}$ 对 Kassjön 湖的研究表明,湖心区沉积物中常量金属元素、重金属与磷、有机碳含量分别为全湖平均值的 $1.25 、 1.5$ 和 1.85 倍. Yang 等 ${ }^{[9]}$ 对英国 Lochnagar 湖的研究表明,沉积速率与金属元素累积通量最大值并不在水深最深的 湖心区. 对西藏普莫雍错与纳木错深水区不同位置岩芯以及表层沉积物的研究 ${ }^{[6,10-12]}$ 也发现, 沉积指标变化 趋势在整体上具有一定的可比性, 但数值上仍具有明显的差异, 如总有机碳含量总体呈现出在深水区富集 的特点, 不同湖区沉积速率空间差异明显. 多岩芯对比分析能够提高对湖泊沉积环境时空演化规律的认识, 但国内外基于多岩芯湖泊环境时空变化与沉积异质性的研究主要集中于浅水湖泊 (水深几米到十几 米) ${ }^{[8-9]}$, 而对大型深水湖泊和湖盆较复杂的湖泊关注较少 ${ }^{[1-12]}$.

我国西南地区高原深水湖泊众多, 人类活动对湖泊与流域环境的影响可追溯到距今 4000 年前 ${ }^{[13]}$. 近百 年来, 随着人类活动影响的进一步增强, 部分湖泊水体污染和生态环境问题日益突出, 如富营养化、重金属 污染、水土流失与湖泊淤积等日益显现 ${ }^{[14-15]}$. 沾沽湖作为西南地区典型的半封闭高原断陷型深水湖泊, 人为 干扰相对较弱. 但随着旅游业和农业的快速发展、流域内人口的快速增加, 沾沽湖也面临着多种生态环境问 题 ${ }^{[16]}$. 关于沾沽湖近百年来环境演化的研究多侧重于湖泊生态系统变化及其对区域气候变化和人类活动 的响应, 如 Zhang 等 ${ }^{[5]} 、$ Guo 等 ${ }^{[17]}$ 研究了摇蚊种群的变化与环境因子的关系, Zhang 等 ${ }^{[18]}$ 研究了沉积物中长 链正构烯烃的变化与生态环境意义, Wang 等 ${ }^{[19]}$ 的研究揭示了表层沉积物硅澡种群组合与水深的关系. 然 而,关于泸沽湖近百年来沉积环境时空变化规律的研究尚无报道.

本文通过对泸沽湖南部湖心区沉积岩芯粒度、磁化率 $\left(X_{\mathrm{If}}\right)$ 、化学蚀变指数 ( CIA ) 等指标的分析以及 ${ }^{210} \mathrm{~Pb}$ 和 ${ }^{137} \mathrm{Cs}$ 定年结果, 结合不同湖区沉积岩芯磁化率与粒度变化的对比、区域降水数据和人类活动等资 料, 研究了近 150 年来沾沽湖沉积环境演化特征; 参考不同湖区沉积岩芯 ${ }^{137} \mathrm{Cs}$ 定年结果, 定量估算近 50 年 来沾沽湖沉积通量, 分析其空间变化规律, 进而探讨人类活动与气候变化对泸沽湖沉积环境时空变化的影 响, 以期为科学全面地认识沾沽湖环境演化过程, 有效实施湖泊及其流域生态环境保护提供科学依据.

\section{1 材料与方法}

\section{1 研究区概况}

沾沽湖 $\left(27^{\circ} 41^{\prime} \sim 27^{\circ} 45^{\prime} \mathrm{N}, 100^{\circ} 45^{\prime} \sim 100^{\circ} 50^{\prime} \mathrm{E}\right.$ ) 位于云南省和四川省之间横断山脉中段东缘尾部金沙江 褶坡带, 行政区上隶属于宁蒗县和盐源县. 泸沽湖湖面海拔 $2690.8 \mathrm{~m}$, 水域面积 $48.5 \mathrm{~km}^{2}$, 最大水深 $93.5 \mathrm{~m}$, 
平均水深 $40.3 \mathrm{~m}^{[14]}$. 泸沽湖集水面积 $171.4 \mathrm{~km}^{2}$, 补给系数 3.54 , 属于半封闭型湖泊 ${ }^{[14]}$. 沾沽湖主要依靠湖 面降水与地表径流补给, 主要人湖河流为三家村河和山跨河等 10 余条溪涧, 湖水通过南部湖区东部的草海 排出人雅䶭江(图 1); 年出入湖水量基本平衡, 湖泊水位年平均变幅在 $1.5 \mathrm{~m}$ 左右 ${ }^{[14]}$. 湖区属于亚热带高原 季风型气候, 年均气温 $12.7^{\circ} \mathrm{C}$, 干湿季节分明,约 $80 \% \sim 90 \%$ 的降水集中于 $5-10$ 月 ${ }^{[5]}$, 多年平均降水量 920 $\mathrm{mm}^{[14]}$. 流域土壤类型垂直分异明显, 海拔 $2800 \mathrm{~m}$ 以下为红壤带, $2800 \sim 3600 \mathrm{~m}$ 为棕壤带, $3600 \mathrm{~m}$ 以上为暗 棕壤 ${ }^{[14]}$. 近年来, 湖水总磷浓度约为 $18.5 \mu \mathrm{g} / \mathrm{L}$, 透明度在 $6.0 \sim 12.0 \mathrm{~m}$ 之间 ${ }^{[20]}$.

沾沽湖流域为摩梭人的世居地, 20 世纪初期以前, 沾沽湖流域内人口密度较小, 以粗放型农业为主, 并 存在小规模的森林砍伐 ${ }^{[21]} .20$ 世纪上半叶, 沾沽湖流域人口逐渐增加, 至新中国成立后, 沾沽湖流域人口增 加了一倍, 目前约 1.3 万人 ${ }^{[20]}$; 随着人口增加, 人类活动对流域环境影响显著加强, 主要包括集约农业发展 和大规模的森林砍伐 ${ }^{[21]}$, 其中农业耕作区主要集中在流域东南部的洪积扇和冲积平原, 其次是在流域东北 部的山前平原. 调查表明, 近年来, 随着泸沽湖自然保护区的建立, 流域植被得以缓慢恢复 ${ }^{[20]}$, 但泸沽湖湿 地资源仍遭到不适当的开发. 同时,生活垃圾和旅游业造成的水环境污染问题也日益明显 ${ }^{[17]}$.

\section{2 样品采集与指标分析}

2012 年, 利用奥地利产 UWITEC 重力采样器在泸沽湖南部湖心区采集了长 $30 \mathrm{~cm}$ 沉积岩芯 (编号为 LGS) (图 1), 所获得的沉积岩芯水土界面清晰, 现场以 $0.5 \mathrm{~cm}$ 间隔分样, 该岩芯上部 (约 $0 \sim 4 \mathrm{~cm}$ ) 为浅棕 色, 中部 (约 4 16 cm) 为土灰色, 下部 (约 $16 \mathrm{~cm}$ 以下) 主要为青灰色, 沉积物质地以粉砂质黏土为主. 2014 年 10 月, 在泸沽湖不同水深湖区又采集了 11 根沉积岩芯 (编号 LGH1 LGH11) (图 1), 现场以 $1 \mathrm{~cm}$ 间隔分 样,岩性特征与 LGS 岩芯相似. 所有沉积物样品均置于密封袋内带回实验室以备分析.

LGS 岩芯样品主要分析粒度、磁化率、金属元素含量以及 ${ }^{210} \mathrm{~Pb}$ 与 ${ }^{137} \mathrm{Cs}$ 活度等, LGH1 LGH11 岩芯除 ${ }^{210}$ $\mathrm{Pb}$ 活度未分析外,其余分析指标与 LGS 岩芯一致. ${ }^{210} \mathrm{~Pb} 、{ }^{226} \mathrm{Ra}$ 和 ${ }^{137} \mathrm{Cs}$ 活度采用美国 $\mathrm{EG} \& \mathrm{G}$ Ortec 公司生产 的高纯锗井型探测器 (HPGe GWL-120-15) 测定. 沉积物低频磁化率使用 Bartington 公司生产的 MS2 型磁化 率测量仪测定 $(0.47 \mathrm{kHz})$, 结合样品重量计算获得质量磁化率. 沉积物样品先后用 $5 \%$ 双氧水、5\%稀盐酸处 理, 分别去除有机质和碳酸盐后, 加人六偏磷酸钠离散剂并超声震荡, 沉积物粒度组成采用英国 Malvern 公 司生产的 Mastersizer 2000 型激光粒度仪进行分析. 沉积岩芯样品冷冻干燥、研磨后, 经盐酸-硝酸-氢氟酸消 解后, 采用电感耦合等离子体原子发射光谱仪 (ICP-AES) 测定金属元素 $(\mathrm{Al} 、 \mathrm{Fe} 、 \mathrm{~K} 、 \mathrm{Na} 、 \mathrm{Ca} 、 \mathrm{Mg} 、 \mathrm{Ti}$ 等) 含量, 分析过程中采用标准参考物质 GBW07358 进行质量控制与精度比对, 各金属元素含量最大误差均小于 7\%. 所有样品测试均在中国科学院南京地理与湖泊研究所湖泊与环境国家重点实验室完成.

根据金属元素含量,计算获得化学蚀变指数 $\left[\mathrm{CIA}=100 \times \mathrm{Al}_{2} \mathrm{O}_{3} /\left(\mathrm{Al}_{2} \mathrm{O}_{3}+\mathrm{K}_{2} \mathrm{O}+\mathrm{Na}_{2} \mathrm{O}+\mathrm{CaO}{ }^{*}\right)\right]^{[22]}$, 式中氧 化物为摩尔质量百分比, 而 $\mathrm{CaO}^{*}$ 指的是硅酸盐矿物中的 $\mathrm{Ca}$ 含量, 不包括碳酸盐和磷酸盐等矿物中结合的 $\mathrm{Ca}$, 本文采用 McLennan 提出的方法进行 $\mathrm{CaO}$ 含量校正 ${ }^{[23]}$. CIA 指示了流域岩土体中长石风化成黏土矿物 的程度,CIA 值越大, 反映物源区化学风化程度越强 ${ }^{[22]}$.

数据分析采用 SPSS 19 统计软件; 沉积指标垂向与空间变化分别采用 Golden Software 公司的 Grapher 9 和 Surfer 10 软件绘制,粒度组成、沉积通量等值线采用克里金插值法.

\section{2 结果与分析}

\section{1 沉积岩芯年代}

LGS 岩芯中 ${ }^{137} \mathrm{Cs}$ 活度在 $10.5 \mathrm{~cm}$ 处存在显著的峰值 (图 2), ${ }^{210} \mathrm{~Pb}_{\mathrm{ex}}$ 活度随深度增加呈指数降低 ${ }^{[18]},{ }^{137} \mathrm{Cs}$ 和 ${ }^{210} \mathrm{~Pb}_{\text {ex }}$ 变化指示了较为稳定的沉积序列, 根据 ${ }^{210} \mathrm{~Pb}_{\mathrm{ex}}$ 与 ${ }^{137} \mathrm{Cs}$ 活度建立的 LGS 岩芯年代结果见文献 [18]. LGS 岩芯年代-深度序列与 Guo 等 ${ }^{[17]}$ 在沾沽湖南部湖心区相邻位置的岩芯研究结果相近, 如 1920 年分别对 应 20 和 $18.5 \mathrm{~cm}, 1980$ 年分别对应 10 和 $11 \mathrm{~cm}$.

LGH1 LGH1 1 沉积岩芯 ${ }^{137} \mathrm{Cs}$ 比活度垂直变化如图 2 所示, 各岩芯中 ${ }^{137} \mathrm{Cs}$ 均出现较明显峰值. 与北半球 大气 ${ }^{137} \mathrm{Cs}$ 沉降通量相比 ${ }^{[24]}$, 沾沽湖沉积岩芯中 ${ }^{137} \mathrm{Cs}$ 峰值深度以下, ${ }^{137} \mathrm{Cs}$ 活度存在明显的拖尾现象, 可能与 还原条件下 ${ }^{137} \mathrm{Cs}$ 垂直扩散有关 ${ }^{[25]}$. 研究表明, 沉积物中 ${ }^{137} \mathrm{Cs}$ 扩散迁移对其峰值所对应的沉积层位不会产生 影响, 并不影响 ${ }^{137} \mathrm{Cs}$ 作为全球核爆事件的时标定年 ${ }^{[24]}$. 不同湖区沉积岩芯 ${ }^{137} \mathrm{Cs}$ 峰型的差别可能与流域侵蚀 


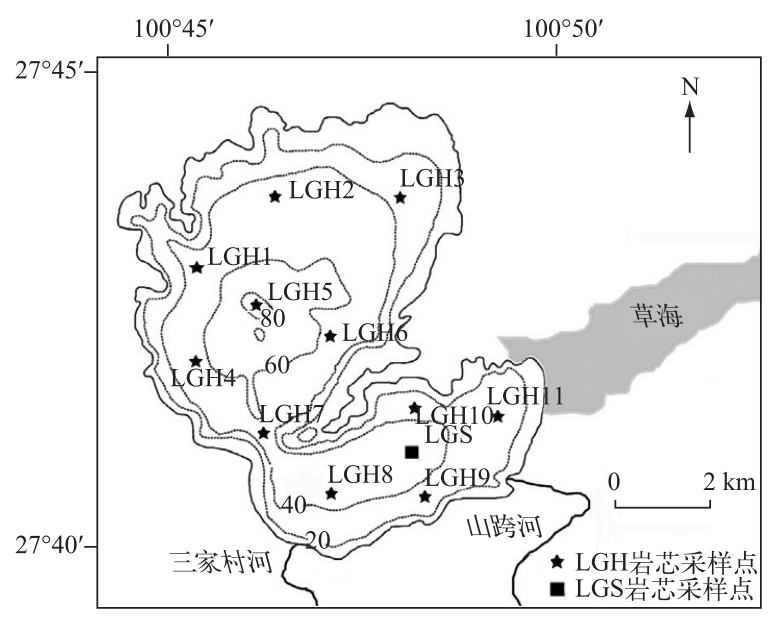

图 1 泸沽湖沉积岩芯采样点位置与编号(图中虚线为水深等值线,根据文献[14]绘制)

Fig.1 Samping sites and numbers of the sediment cores from Lake Lugu

二次输人等因素有关 ${ }^{[24]}$. Wan 等 ${ }^{[26]}$ 对云南深水湖泊的研究表明, 由大气沉降到水体中 ${ }^{137} \mathrm{Cs}$ 需要一年左右 的滞留时间才能完全到达湖泊沉积物中. 对照 ${ }^{137} \mathrm{Cs}$ 在北半球的大气沉降规律 ${ }^{[24]}$, 沾沽湖各岩芯 ${ }^{137} \mathrm{Cs}$ 峰值深 度对应于 1964 年(图 2)。

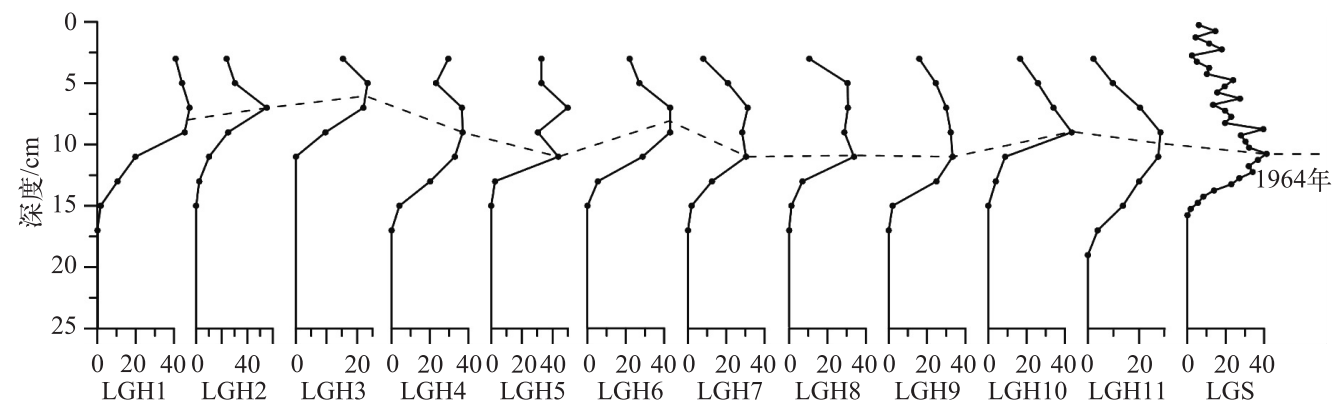

图 2 泸沽湖沉积岩芯 ${ }^{137} \mathrm{Cs}$ 活度变化 $(\mathrm{Bq} / \mathrm{kg})$

Fig. 2 Variation of ${ }^{137}$ Cs activities in sediment cores from Lake Lugu

\subsection{LGS 岩芯沉积指标变化特征}

LGS 岩芯沉积物粒度组成以黏土和细粉砂为主, 其中黏土 $(<4 \mu \mathrm{m})$ 含量为 $41 \% \sim 70 \%$, 平均值为 $49 \%$; 细粉砂 (4 16 $\mu \mathrm{m}$ ) 含量为 $26 \% \sim 42 \%$, 平均值为 $36 \%$; 粗粉砂 (16 63 $\mu \mathrm{m}$ ) 与砂 ( $\geqslant 63 \mu \mathrm{m}$ ) 的平均含量分别 为 $15 \%$ 和 $1 \%$. 磁化率值为 $70 \times 10^{-8} \sim 428 \times 10^{-8} \mathrm{~m}^{3} / \mathrm{kg}$, 平均值为 $204 \times 10^{-8} \mathrm{~m}^{3} / \mathrm{kg}$. CIA 值变化范围为 $81.8 \sim$ 85.9 , 均值为 83.3 , 指示沉积物经历了较强的化学风化 ${ }^{[22]}$. 垂向上, 深度 $20 \mathrm{~cm}$ (1920 年) 以下沉积物粒度组 成较稳定, 砂含量有所波动但总体较小 (平均为 $2 \%$ ), 磁化率与 CIA 值较低且变化较小; $20 \sim 10 \mathrm{~cm}(1920-$ 1970 年), 黏土含量、磁化率与 CIA 值均逐渐升高, 中值粒径逐渐降低; 10 3.5 cm (1970-2002 年), 各沉积 指标延续了上一阶段的变化趋势, 但增加/降低更加明显; $3.5 \mathrm{~cm}$ 以上 (2002 年以来), 黏土含量、磁化率与 CIA 值均逐渐降低 (图 3).

\section{3 不同湖区沉积岩芯磁化率与粒度的垂向变化}

沾沽湖不同湖区沉积岩芯 CIA 值、黏土含量变化趋势与磁化率相似, 具有显著相关性 $(r>0.85, P<0.01)$, 本文主要对磁化率与粒度进行分析. LGH1 LGH11 沉积岩芯中磁化率值为 $55 \times 10^{-8} \sim 559 \times 10^{-8} \mathrm{~m}^{3} / \mathrm{kg}$, 平均为 $207 \times 10^{-8} \mathrm{~m}^{3} / \mathrm{kg}$. 不同水深湖区沉积岩芯磁化率垂向变化规律与 LGS 岩芯相似 ( 图 4), 沉积岩芯下部磁化率 


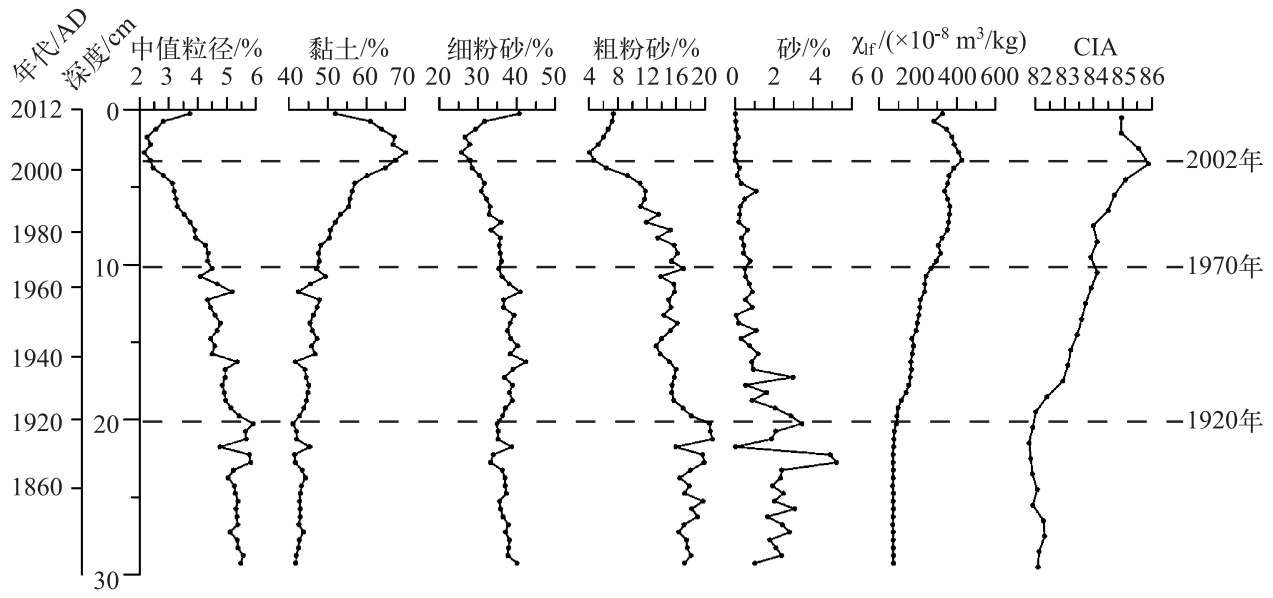

图 3 泸沽湖 LGS 岩芯粒度、磁化率与 CIA 的变化

Fig.3 Variation of grain size, magnetic susceptibility and CIA in core LGS from Lake Lugu

较低且相对稳定; 沉积岩芯中部磁化率逐渐上升, 沉积岩芯顶部磁化率逐渐降低. 但不同沉积岩芯磁化率开 始出现增加的深度不同, 如 LGH3、LGH5 岩芯磁化率分别在 12 和 $23 \mathrm{~cm}$ 处开始增加, 具有明显差别, 可能与 上述两个岩芯所处湖区沉积速率差异有关. 基于 LGS 岩芯年代序列, 可以初步确定泸沽湖各沉积岩芯下部 磁化率开始出现增加的层位对应于约 1920 年 (图 4). 为了进一步对比不同沉积岩芯磁化率与粒度的变化趋 势, 采用沉积岩芯顶部样品作为参照对各沉积岩芯的磁化率与黏土含量进行归一化. 结果显示, 各指标垂向 变化趋势一致 (图 5), 指示沾沽湖不同水深湖区沉积环境演化趋势具有相似性, 这与纳木错等湖泊研究结果 一致 ${ }^{[12]}$; 但不同沉积岩芯指标变化幅度仍存在一定的差别 (图 5), 说明沾沽湖沉积特征存在一定的空间异 质性.

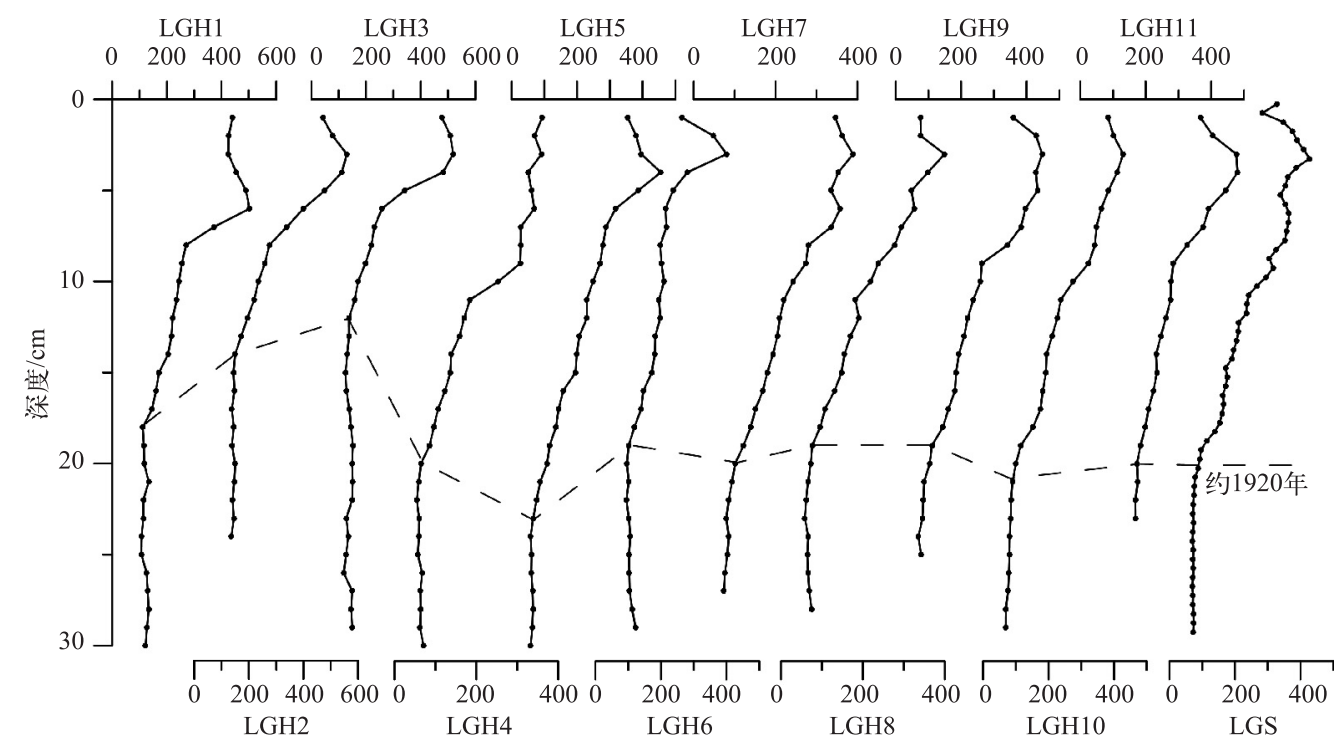

图 4 泸沽湖沉积岩芯磁化率垂向变化 $\left(\times 10^{-8} \mathrm{~m}^{3} / \mathrm{kg}\right)$

Fig.4 Vertical variations of magnetic susceptibility in the sediment cores from Lake Lugu 

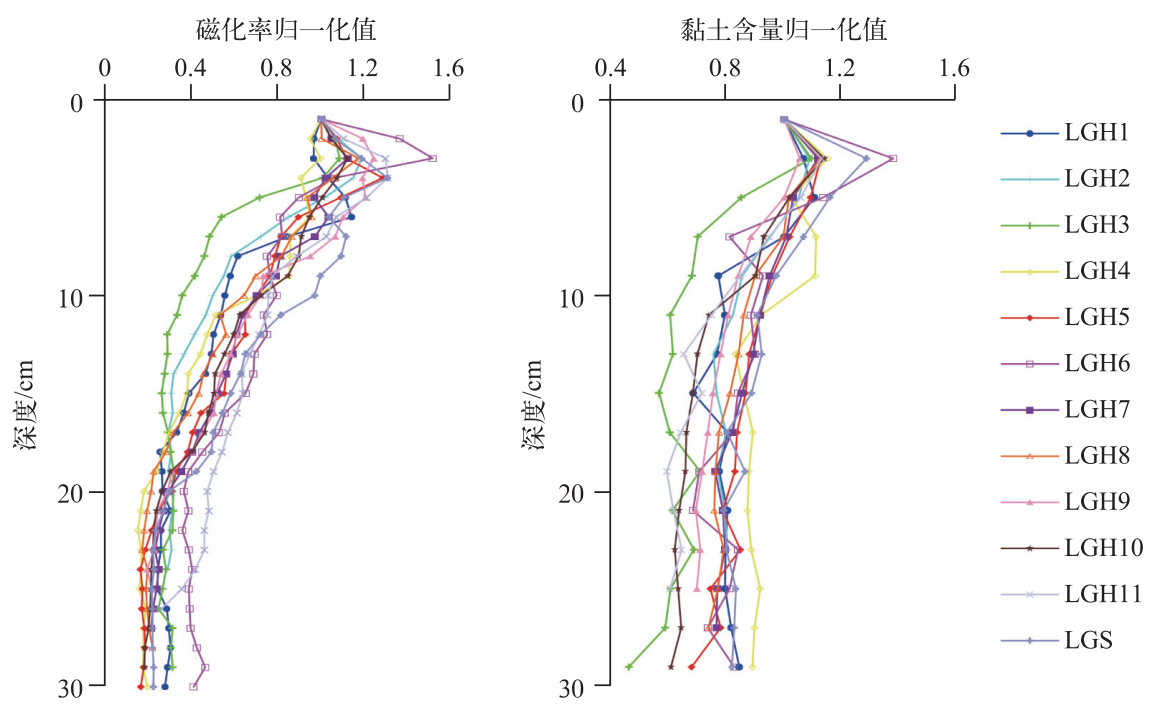

图 5 泸沽湖沉积岩芯磁化率和黏土含量的归一化图

Fig.5 Normalized curves of magnetic susceptibility and clay content in the sediment cores from Lake Lugu

\section{4 沉积通量和粒度组成的空间变化}

依据各岩芯 1964 年时标所对应的深度以及单位面积沉积物干重,计算获得近 50 年来沾沽湖的平均沉 积通量为 $0.020 \sim 0.043 \mathrm{~g} /\left(\mathrm{cm}^{2} \cdot \mathrm{a}\right)$, 算术平均值为 $0.031 \mathrm{~g} /\left(\mathrm{cm}^{2} \cdot \mathrm{a}\right)$. 空间上,沉积通量总体呈由南部湖区 向北部湖区逐渐降低的规律 (图 6), 南部湖区沉积通量算术平均值 $\left(0.038 \mathrm{~g} /\left(\mathrm{cm}^{2} \cdot \mathrm{a}\right)\right)$ 为北部湖区 $(0.024$ $\left.\mathrm{g} /\left(\mathrm{cm}^{2} \cdot \mathrm{a}\right)\right)$ 的 1.58 倍. 各湖区沉积通量也存在一定空间差异, 如北部湖区东部浅水区沉积通量相对较低, 南部湖区近南岸区域沉积通量较高 (图 6). 近 50 年来泸沽湖沉积物中黏土平均含量也存在一定空间差异, 北部湖区北部水域和南部湖区东南部水域沉积物中黏土含量相对较高. 统计分析表明, 各岩芯 1964 年以来 的平均沉积通量与水深、黏土平均含量均无显著相关性 $(r<0.50, P>0.20)$.

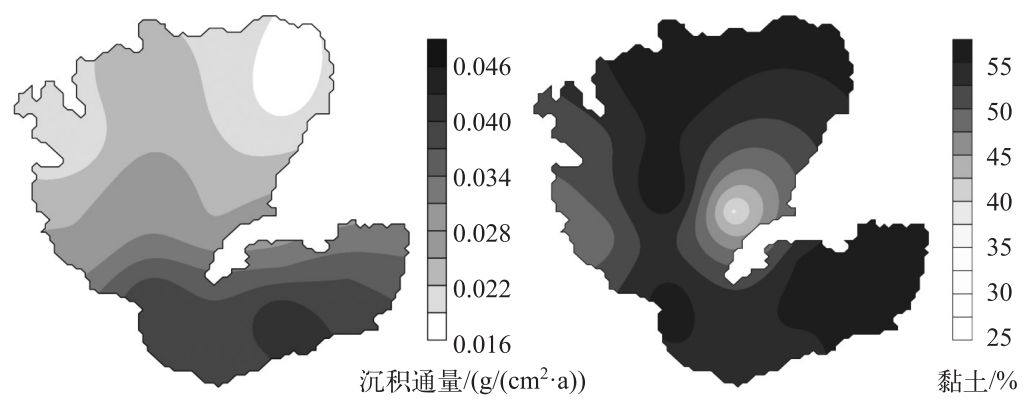

图 61964 年以来泸沽湖平均沉积通量以及黏土百分含量等值线图

Fig.6 Contour maps of the average mass accumulation rates and clay percentage since 1964 in Lake Lugu

选取各沉积岩芯 1920 年层位 (文中 2.3 节所述) 以下 3 个样品,代表人类活动影响较弱的准自然阶段沉 积物, 选取各岩芯 1964 年深度和顶部样品, 对比分析了各时期黏土含量的变化(图 7 ). 结果显示, 不同时期 沉积物黏土含量空间分布规律总体相似, 北部与南部湖区近岸区域秥土含量较高, 北部湖区东南部黏土含 量较低. 时间上, 3 个时段黏土平均含量分别为 39\%、48\% 和 53\%, 呈逐渐增加的趋势, 这与 LGS 沉积岩芯黏 土含量变化结果一致; 与 1920 年之前相比, 1964 年沉积物与表层沉积物中黏土含量在南部湖区东部和北部 湖区北部增加较明显. 


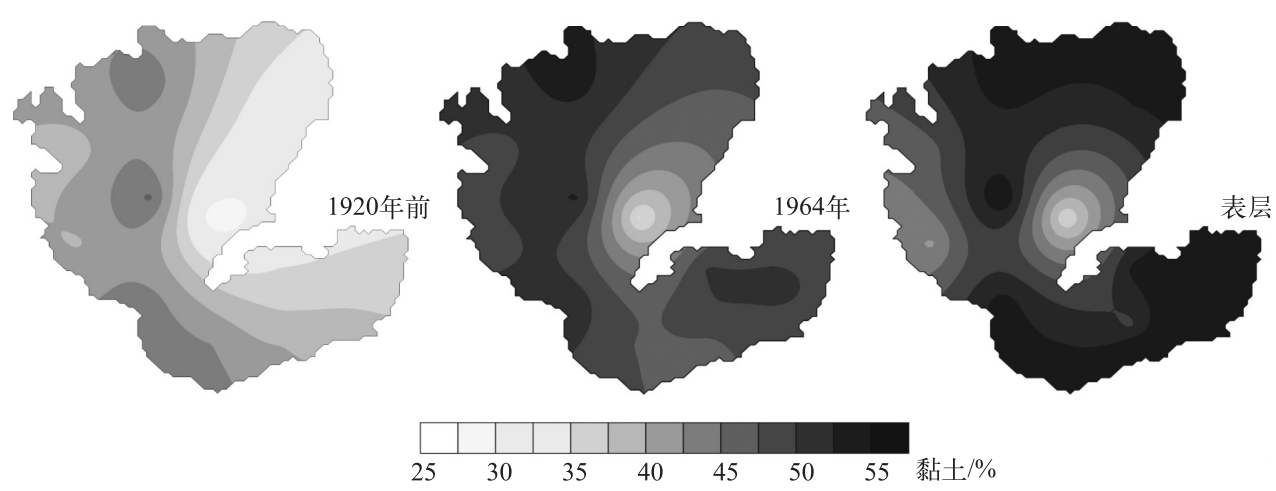

图 7 泸沽湖不同时期沉积物黏土百分含量等值线图

Fig.7 Contour maps of clay percentages in sediments of Lake Lugu at different periods

\section{3 讨论}

\section{1 泸沽湖沉积环境演变与影响因素}

近 150 年以来泸沽湖沉积指标发生了两次明显变化, 1920 年以前,沉积物粒度组成相对稳定, 磁化率值 和 CIA 值较低, 说明沉积环境和流域物质输人较稳定; 1920 年以来, 沉积指标与前期相比发生明显变化, 黏 土含量、磁化率与 CIA 值均逐渐升高, 反映了风化程度较高的富含磁性矿物的细颗粒物质增加, 同时湖泊沉 积通量升高 ${ }^{[18]} ; 2002$ 年以来, 黏土含量、磁化率与 CIA 值均逐渐降低.

沾沽湖作为一个半封闭高山深水淡水湖泊, 入湖河流都十分短小, 其沉积物无机组分主要来自流域土 壤和风化的岩石碎屑 ${ }^{[5,14]}$. 与浅水湖泊沉积物粒度组成受到水位变化影响较大不 同 $^{[27]}$, 泸沽湖平均水深 $40.3 \mathrm{~m}$, 水位波动较小, 同一采样点沉积岩芯中粒度变化受湖泊水位波动影响较小, 地表径流强度、侵蚀模式 与物源是影响沉积物粒度的主要因素, 其中降水量变化通过影响地表径流强度而在相当程度上决定着进人 湖泊的陆源颗粒物组成 ${ }^{[27-29]}$. 降水量大的年份, 地表径流发育, 其剥蚀和搬运能力增强, 沉积物粒径增大, 反 之沉积粒度粒径降低 ${ }^{[27-28]}$. 结合丽江气象站 1950 年以来的降水资料, 对比研究了 LGS 岩芯沉积物中值粒径 与降水量的变化 (图 8). 结果显示, 二者变化趋势明显不同,如 1960 年前后降水量较少而沉积物中值粒径偏 大; 1960-1965 年前后, 降水量偏高而中值粒径较小; 1965-2000 年前后中值粒径逐渐减小, 而降水量呈现 出先减小、1980s 中期以后又逐渐增加的趋势. 虽然 1998-2008 年前后中值粒径与降水量变化趋势一致,均 逐渐减小,但从整个对比时段 (1950 年以来) 来看, 1998-2008 年的几乎是近 60 年平均降水量偏高的时期, 而中值粒径却处于相对低值. 此外, 1950 年以来降水量在 1963、1983、1990、2000 年前后均出现峰值, 而沉积 物中值粒径并未呈现出相应的增加特征, 这与已有研究中降水量对沉积物粒度组成影响的认识不同 ${ }^{[27-29]}$. 相关性分析也表明, 1950 年以来降水量与沉积物中值粒径无显著的相关关系 $(n=30, r=-0.345, P=0.067)$. 因此, 作者认为本研究时段内沾沽湖沉积物粒度组成变化受降水等气候影响相对较弱, 这与人类活动影响 较弱的纳木错粒度组成等沉积指标主要受气候影响明显不同 ${ }^{[11]}$.

除了降水量之外, 流域土壤侵蚀模式与物源的变化对沉积物粒度及磁化率也会产生一定影响 ${ }^{[29-30]}$. 土 壤侵蚀可分为面蚀、细沟侵蚀、冲沟侵蚀与沟岸侵蚀等 ${ }^{[31]}$, 主要受地形、降水以及土地覆被的影响. 与深层 土壤相比, 表层土壤由于经历了较强的风化与成壤作用, 其粒级组成较小, 具有较高的 CIA 值, 我国热带、亚 热带地区 (如云南) 红色风化壳的富铁铝化和 “磁赤铁矿化” 使得表层土壤中铁磁性物质丰富 ${ }^{[32]}$, 磁化率较 高; 而深层土壤所经历的化学风化作用相对较弱, 不完整反铁磁性矿物含量较高 ${ }^{[33]}$, 磁化率较低. 流域植被 覆盖较高时, 土壤侵蚀以细沟侵蚀、冲沟侵蚀与沟岸侵蚀为主, 水流所携带的颗粒物主要来自更多的深层土 壤, 粒度组成较粗, 沉积物磁化率较低 ${ }^{[34]}$; 森林砍伐等人类活动影响使得地表破碎度增加, 表层土壤由于缺 乏植被的保护, 易受到降水侵蚀的影响, 人湖颗粒物中来自土壤面蚀的比重增加, 带人水体的富含铁磁性物 质的细颗粒物比例增加 ${ }^{[34-35]}$. 


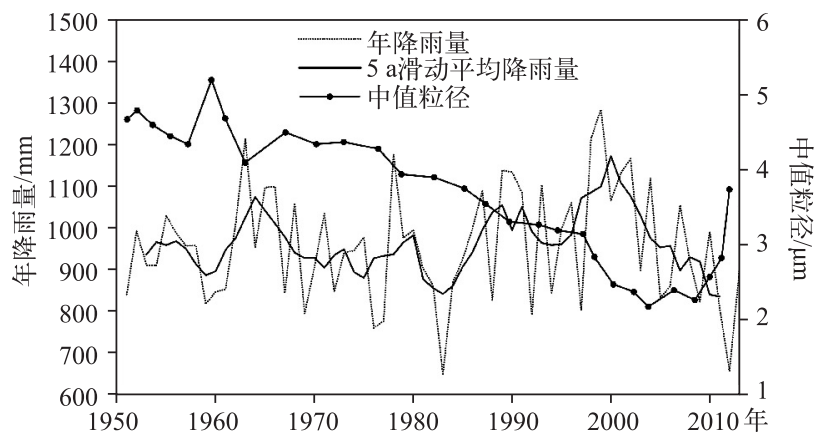

图 8 1951－2012 年丽江气象站年降水量与 LGS 岩芯中值粒径变化

Fig. 8 Variation of annual rainfall in Lijiang weather station from 1951 to 2012 and median diameter of core LGS

根据相关资料 ${ }^{[21,36]}$, 摩梭人世居于川滇交界地区, 清朝以后, 居住范围缩小, 主要集中在四川盐源县和 云南宁蒗县的沪沽湖周围地区. 20 世纪初期以来, 摩梭族与外界沟通加强, 泸沽湖流域人口增加、人类活动 对流域环境影响开始加剧, 这可能对应着 1920 年左右湖泊沉积指标开始发生变化. 新中国成立以来, 泸沽 湖流域人类活动强度进一步增加, 主要包括大规模森林砍伐和农业发展, 水土流失问题日益显现 ${ }^{[21]}$. 随着 沾沽湖流域人类活动对流域原有植被的持续破坏, 表层松散土壤抗侵蚀能力减弱, 风化与成壤作用较强的 细颗粒表土物质人湖比例增加, 由此导致沪沽湖沉积物黏土含量增加、中值粒径减小, 湖泊沉积通量上 升 $^{[17]}$. 1970s 和 1980s 初期沾沽湖流域发生了两次大规模砍伐 ${ }^{[20]}$, 这可能是 1970 年后沉积物黏土含量与磁 化率快速升高的主要原因. 对泸沽湖流域 22 个表土与岩石样品分析表明 (尚未发表资料), 表土磁化率平均 为 $575 \times 10^{-8} \mathrm{~m}^{3} / \mathrm{kg}$, 而基岩样品磁化率平均仅为 $41 \times 10^{-8} \mathrm{~m}^{3} / \mathrm{kg} ; 1970 \mathrm{~s}$ 以来沉积物磁化率与表土磁化率较为 接近, 反映了流域表土侵蚀对泸活湖沉积环境的影响. 虽然 1986 年 “沾沽湖省级自然保护区”成立, 但人湖 物质成分与前期相比没有明显改变. Bai 等 ${ }^{[20]}$ 研究表明, 1995-2005 年泸沽湖流域农业用地减少了 $44.9 \%$, 林地与草地增加了 $54.8 \%$; 近年来沾沽湖流域森林覆盖率由 2003 年的 $54.5 \%$ 增加到 $68.7 \%{ }^{[37]} .2002$ 年以 来, 细颗粒沉积物含量、磁化率与 CIA 值均有所降低( 图 3、4), 可能与沾沽湖流域近年来地表植被逐渐恢复 等环境保护措施的实施导致流域表土侵蚀减弱有关. 此外, 近 10 年以来降水减少, 中值粒径升高, 磁化率与 CIA 值降低, 还可能与人类活动影响的减弱, 降水对泸沽湖物源输人的影响增强有关 (图 $3 、 8$ ). 泸沽湖流域 森林砍伐和农业发展导致的土壤侵蚀条件改变及其对湖泊沉积环境的影响与 $\mathrm{Wang}$ 等 $^{[34]}$ 对贵州石板桥水 库和小河水库的研究结论一致, 并与星云湖和洱海流域早期 (AD 500-1050) 森林砍伐及农业发展等人类活 动对湖泊沉积环境的影响相似 ${ }^{[4,38]}$, 但类似的早期人类活动对流域与湖泊沉积环境的影响在沪沽湖地区是 否存在, 还有待进一步研究.

近 150 年来沪沽湖沉积环境演变与我国西南地区的其他湖泊具有相似的特征, 如抚仙湖近代沉积环境 开始变化于 $1930 \mathrm{~s}$, 主要受到围垦、流域水系变化和工矿业活动的影响 ${ }^{[29]}$; 洱海和属都湖沉积环境变化与 $1950 \mathrm{~s}$ 以来流域农业活动、水利工程修建息息相关 ${ }^{33]}$. 然而, 在人类活动方式与强度及其对湖泊生态环境影 响程度等方面仍存在一定的差异, 如营养盐输人与外来鱼种的引人是洱海、程海及抚仙湖等浮游动植物种 群等生态环境发生显著改变的主要影响因素 ${ }^{[39-40]}$; 而结合本文和相关研究 ${ }^{[5,17-18]}$, 认为沪沽湖生态环境变化 主要受到流域土壤侵蚀、气温以及近年来生活污水输人的影响, 其中黏土等细颗粒组分的增加导致的水体 透明度下降是 $1970 \mathrm{~s}-1980 \mathrm{~s}$ 以来沪沽湖水生生物种群组成和结构发生改变的主要影响因素之一 ${ }^{[5]}$.

\section{2 沪沽湖沉积空间异质性分析}

沾沽湖沉积通量总体呈由南部湖区向北部湖区逐渐降低的规律 (图 6). 众多研究表明 ${ }^{[7-8,10,41]}$, 受湖泊 水深与水下地形、湖流等影响, 由近岸区域至湖心通常可划分为侵蚀带、过渡带与沉积物累积带, 沉积通量 一般由浅水区至深水区逐渐增加. 鉴于沾沽湖南北两个湖区水深的差异, 对采样点较多、水深变化较大的泸 沽湖北部湖区各岩芯 1964 年以来的平均沉积通量与采样点水深进行相关性分析, 结果表明二者无典型相 
关性 $(n=7, r=0.52, P=0.23)$, 说明水深对泸沽湖沉积通量空间变化影响较小, 这与国外部分研究结果一 致 ${ }^{[8]}$. 除了湖泊内部环境因素, 陆源物质输人是影响湖泊沉积通量的主要因素 ${ }^{[41]}$. 沾沽湖流域南部发育面 积较大的洪积扇和冲积平原, 20 世纪初期特别是建国后逐渐被发展为流域内主要的农业基地, 但由于土层 痊薄, 不易保水, 农民为改良土壤而从山林中运土到湖滨耕地 ${ }^{[42]}$, 加重了这些区域的水土流失; 泸沽湖人湖 水系中最主要的两条河流 (三家村河和山跨河) 分别位于南部湖区的西南部和东南部. 因此, 我们认为人类 活动 (如森林砍伐、农业开脣) 及人湖河流分布可能是导致南部湖区沉积通量较高的主要原因. 此外, 泸沽湖 唯一的出水口位于东南部, 湖水经由草海流出, 东南部湖区水生植被较为发育, 水生植物的阻拦作用也利于 沉积物的堆积 ${ }^{[43]}$, 是造成东南部湖区沉积通量较高的重要影响因素. 总之, 近 50 年来沾沽湖沉积通量空间 变化主要受控于流域人为活动造成的陆源物质输人; 而纳木错的相关研究表明, 其沉积通量主要受水深、水 下地形以及人湖河流分布的影响 ${ }^{[11]}$.

物源与水动力条件被认为是影响湖泊沉积物粒度组成的主要因素 ${ }^{[27]}$, 受湖泊水动力的影响, 由湖岸到 湖心沉积物粒度组成逐渐变细 ${ }^{[28]}$. 然而, 沾沽湖南部和北部湖区近岸区域采样点黏土含量较高 (图 6、7), 不 同时期沉积物中黏土含量与水深无显著相关性 (北部湖区, $n=7, r<0.05, P>0.90$ ), 并且 1964 年以来的黏土 平均含量和平均沉积通量也无显著相关性 $(n=12, r=0.40, P=0.21)$, 这与上述湖泊沉积物粒度空间变化主 要受湖泊水深与水动力影响的观点不一致. 结合前文分析, 认为泸沽湖沉积物粒度空间变化可能主要受物 源区土壤粒度组成的影响, 毗邻流域人类活动强烈影响的湖区沉积物粒度组成更细, 如流域东南部和东北 部的主要农业耕作区附近湖区的沉积物黏土含量较高 (图 7).

研究表明 ${ }^{[7-8]}$, 湖泊水下地形坡度 $<3 \%$ (坡度百分比, 即高程增量与水平距离之比) 的区域主要为堆积 区, 沉积环境比较稳定; 而水下地形坡度 $>10 \%$ 的湖区, 以侵蚀搬运作用为主. 沾沽湖沉积通量与黏土含量并 未表现出随水深增加而升高的规律, 除了与流域物源输人有关之外, 还与南部湖区沉积岩芯采样点水深大于 $20 \mathrm{~m}$, 北部湖区沉积岩芯采样点水深大于 $40 \mathrm{~m}$, 与近岸区域相比, 本研究采样点水下地形相对平缓 (坡度 $<$ $3.3 \%$ ) 有关. 沾沽湖水下地形坡度较大的近岸区域理论上存在一定的冲刷作用, 其沉积通量及沉积物粒度 组成与深水区可能存在一定差异, 还需补充采样进一步研究.

\section{4 结论}

近 150 年沾沽湖沉积环境演化具有明显的阶段性特征, 1920 年之前, 沉积物磁化率、CIA 与粒度组成变 化较小, 流域物质输人较为稳定, 反映了人类活动影响较弱的准自然演化阶段; 1920 年开始, 特别是 1970 年 以来, 沉积物中黏土含量、磁化率、CIA 值均明显升高, 反映了风化程度较高的细颗粒表土物质侵蚀加强, 这 主要与流域人口增加及人类活动影响加剧 (如森林砍伐和农业耕作等) 有关. 沪沽湖不同水深湖区沉积指标 变化趋势相似, 但变幅仍具有较大不同, 指示了沉积特征的空间差异. 近 50 年来南部湖区的平均沉积通量 高于北部湖区, 与流域内水系分布和人类活动强度的空间特征一致. 沉积物中粒度组成主要与人类活动影 响下的物质来源有关, 隸土等细颗粒含量高值主要分布于毗邻流域农业等人类活动影响较大的南部与北部 近岸湖区. 泸沽湖多岩芯分析表明, 采用深水区单一岩芯沉积指标能够反映沉积环境演化趋势, 但鉴于沉积 通量与沉积环境的空间异质性, 在碳埋藏和重金属等污染物累积定量研究方面宜采用多岩芯综合分析.

致谢: 羊向东研究员、王倩博士、陈嵘博士参加野外采样并协助进行磁化率分析, 朱育新副研究员、蔡艳杰协 助完成金属元素测定,夏威岗高级工程师完成沉积岩芯年代测定,在此深表感谢.

\section{5 参考文献}

[ 1 ] Shen Ji. Progress and prospect of palaeolimnology research in China. J Lake Sci, 2009, 21(3) : 307-313. DOI: 10.18307/ 2009.0301. [沈吉. 湖泊沉积研究的历史进展与展望. 湖泊科学, 2009, 21 (3) : 307-313.]

[ 2 ] Bindler R, Rydberg J, Renberg I. Establishing natural sediment reference conditions for metals and the legacy of longrange and local pollution on lakes in Europe. Journal of Paleolimnology, 2011, 45(4) : 519-531. DOI: 10.1007/s10933010-9425-5.

[ 3 ] Wang R, Dearing JA, Peter GL et al. Flickering gives early warning signals of a critical transition to a eutrophic lake state. Nature, 2012, 492(7429) : 419-422. DOI: 10.1038/nature11655. 
[ 4 ] Dearing JA, Yang X, Dong X et al. Extending the timescale and range of ecosystem services through paleoenvironmental analyses, exemplified in the lower Yangtze basin. Proceedings of the National Academy of Sciences, 2012, 109(18): E1111-E1120. DOI: 10.1073/pnas.1118263109.

[ 5 ] Zhang EL, Tang HQ, Cao YM et al. The effects of soil erosion on chironomid assemblages in Lugu Lake over the past 120 years. International Review of Hydrobiology, 2013, 98(3) : 165-172. DOI: 10.1002/iroh.201301468.

[ 6 ] Wang Junbo, Zhu Liping, Ju Jianting et al. Environmental changes reflected by a comparative proxy study among multiple cores from Pumoyum Co, Tibet in the last 200 years. J Lake Sci, 2009, 21(6) : 819-826. DOI:10.18307/2009.0611. [王 君波, 朱立平, 鞠建廷等. 西藏普莫雍错不同岩芯环境指标的对比研究及其反映的近 200 年来环境变化. 湖泊科 学, 2009, 21(6): 819-826.]

[ 7 ] Engstrom DR, Rose NL. A whole-basin, mass-balance approach to paleolimnology. Journal of Paleolimnology, 2013,49 (3) : 333-347. DOI: $10.1007 /$ s10933-012-9675-5.

[ 8 ] Rippey B, Anderson NJ, Renberg I et al. The accuracy of methods used to estimate the whole-lake accumulation rate of organic carbon, major cations, phosphorus and heavy metals in sediment. Journal of Paleolimnology, 2007, 39(1) : 83-99. DOI: 10.1007/s10933-007-9098-x.

[ 9 ] Yang HD, Rose NL, Battarbee RW et al. Trace metal distribution in the sediments of the whole lake basin for Lochnagar, Scotland: a palaeolimnological assessment. Hydrobiologia, 2012, 479(1/2/3) : 51-61. DOI:10.1023/A :1021054112496.

[10] Wang JB, Zhu LP, Nishimura M et al. Spatial variability and correlation of environmental proxies during the past 18,000 years among multiple cores from Lake Pumoyum Co, Tibet, China. Journal of Paleolimnology, 2009, 42(3) : 303-315.

[11] Wang Junbo, Zhu Liping, Wang Yong et al. Spatial variability of recent sedimentation rate and variations in the past 60 years in Nam Co, Tibetan Palteau, China. Quaternary Sciences, 2011, 31(3) : 535-543. [王君波, 朱立平, 汪勇等. 西 藏纳木错现代沉积速率的空间分布特征及近 60 年来的变化研究. 第四纪研究, 2011, 31(3) : 535-543.]

[12] Wang Y, Zhu LP, Wang JB et al. The spatial distribution and sedimentary processes of organic matter in surface sediments of Nam Co, Central Tibetan Plateau. Chin Sci Bull, 2012, 57(32) : 3090-3099. DOI : 10.1007/s11434-012-5500-9.

[13] Dearing JA, Jones RT, Shen J et al. Using multiple archives to understand past and present climate-human-environment interactions: The lake Erhai catchment, Yunnan Province, China. Journal of Paleolimnology, 2008, 40(1) : 3-31. DOI: 10.1007/s10933-007-9182-2.

[14] Wang Sumin, Dou Hongshen eds. China lakes record. Beijing: Science Press, 1998. [王苏民, 窦鸿身. 中国湖泊志. 北 京: 科学出版社, 1998.]

[15] Shi Zhengtao, Ming Qingzhong, Zhang Hucai. Investigation of the evolution and envirnoment change of typical lakes in Yunnan. Journal of Geomechanics, 2004, 10(4): 344-350. [史正涛, 明庆忠, 张虎才. 云南高原典型湖泊演化及环 境变化初步考察. 地质力学学报, 2004, 10(4): 344-350.]

[16] Liu GH, Liu ZF, Hu HF et al. The impact of tourism on agriculture in Lugu Lake region. International Journal of Sustainable Development and World Ecology, 2008, 15(1) : 3-9. DOI : 10.1080/13504500809469762.

[17] Guo XC, Potito AP, Luo L et al. Twentieth century human and climate impacts on a large mountain lake in southwest China. Hydrobiologia, 2013, 718(1) : 189-206. DOI: 10.1007/s10750-013-1615-5.

[18] Zhang YD, Su YL, Liu ZW et al. Long-chain n-alkenes in recent sediment of Lake Lugu ( SW China) and their ecological implications. Limnologica, 2015, 52(1) :30-40. DOI: 10.1016/j.limno.2015.02.004.

[19] Wang Q, Yang XD, Hamilton PB et al. Linking spatial distributions of sediment diatom assemblages with hydrological depth profiles in a plateau deep-water lake system of subtropical China. Journal of the Czech Phycological Society, 2012, 12(1) :59-73. DOI: $10.5507 /$ fot.2012.005.

[20] Bai X, Ma KM, Yang L et al. Simulating the impacts of land-use changes on non-point source pollution in Lugu Lake watershed. International Journal of Sustainable Development and World Ecology, 2008, 15 (1): 18-27. DOI: 10. 1080/13504500809469764.

[21] Wan Ye, Guo Laixi. Crisis factors and control approaches of the special natural-social ecological system of the Lugu Lake area. Resources and environment in Yangtze Valley, 1997, 6(3): 211-215. [万晔, 郭来喜. 泸沽湖区特殊自然社会生 态系统的危机因素及调控途径. 长江流域资源与环境, 1997, 6(3): 211-215.]

[22] Nesbitt HW, Young GM. Early proterozoic climates and plate motions inferred from major element chemistry of lutites. Nature, $1982,299(5885)$ : 715-717.

[23] McLennan SM. Weathering and global denudation. The Journal of Geology, 1993, 101: 295-303.

[24] Last WM, Smol JP. Tracking environmental change using lake sediments. Volume 1: Basin analysis, coring, and chronological techniques, 2001. 
[25] Yang H, Turner S. Radiometric dating for recent lake sediments on the Tibetan Plateau. Hydrobiologia, 2013, 713( 1): 73-86. DOI: $10.1007 /$ s10750-013-1493-x.

[26] Wan GJ, Chen JA, Wu FC et al. Coupling between ${ }^{210} \mathrm{~Pb}_{\mathrm{ex}}$ and organic matter in sediments of a nutrient-enriched lake: An example from Lake Chenhai, China. Chemical Geology, 2005, 224 (4) : 223-236. DOI: 10.1016/j. chemgeo. 2005. 07.025 .

[27] He Huachun, Ding Haiyan, Zhang Zhenke et al. Grain-size characteristics and their environmental significance of Hongze Lake sedments. Scientia Geographica Sinica, 2005, 25(5): 590-596. [何华春, 丁海燕, 张振克等. 淮河中下游洪泽 湖湖泊沉积物粒度特征及其沉积环境意义. 地理科学, 2005, 25(5): 590-596.]

[28] Chen Jing'an, Wan Guojiang, Zhang Feng et al. Lake sediment environmental records under different time scales-a case study of sediment grain-size. Science in China: Series D: Earth Sciences, 2004, 33(6): 563-568. [ 陈敬安, 万国江, 张 峰等. 不同时间尺度下的湖泊沉积物环境记录——沉积物粒度为例. 中国科学: D 辑: 地球科学, 2004, 33(6): 563-568.]

[29] Wang Xiaolei, Yang Hao, Zhao Qiguo et al. Recent environmental change inferred from grain-size records in Fuxian Lake, Yunnan Province. Acta Sedimentologica Sinca, 2010, 28(4): 776-782. [王小雷, 杨浩, 赵其国等. 云南抚仙湖近现代 环境变化的沉积物粒度记录. 沉积学报, 2010, 28(4): 776-782.]

[30] Wu Ruijin. The magnetic susceptibility, frequency magnetic susceptibility of lake sediments and its paleoclimatic significance. J Lake Sci, 1993, 5(2) : 128-135. DOI:10.18307/1993.0204. [ 吴瑞金. 湖泊沉积物的磁化率、频率磁化率及 其古气候意义. 湖泊科学, $1993, \mathbf{5}(2):$ 128-135.]

[31] He Xiubin, Zhang Xinbao, Walling DE. The basin erosion rate calculation model based on deposit profile ${ }^{137}$ Cs changes of lake and reservoir. Progress in Natural Science, 2005, 15(4) : 495-498. [贺秀斌, 张信宝, Walling DE. 基于湖库沉积 剖面 ${ }^{137} \mathrm{Cs}$ 变化的流域表层侵蚀速率计算模型. 自然科学进展, 2005, 15(4) : 495-498.]

[32] Huang Zhenguo ed. Red weathering crust in southern China. Beijing: Ocean Press, 1996. [黄镇国. 中国南方红色风化 壳. 北京: 海洋出版社, 1996.]

[33] Little MG, Lee CTA. Sequential extraction of labile elements and chemical characterization of a basaltic soil from Mt. Meru, Tanzania. J Afr Earth Sci, 2010, 57(5) : 444-454. DOI: 10.1016/j.jafrearsci.2009.12.001.

[34] Wang H, Xu L, Sun X et al. Comparing mineral magnetic properties of sediments in two reservoirs in “strongly" and “mildly” eroded regions on the Guizhou Plateau, southwest China: A tool for inferring differences in sediment sources and soil erosion. Geomorphology, 2011, 130(3) : 255-271. DOI:10.1016/j.geomorph.2011.04.003.

[35] McDonald MA, Healey JR, Stevens PA. The effects of secondary forest clearance and subsequent land-use on erosion losses and soil properties in the Blue Mountains of Jamaica. Agric Ecosyst Environ, 2002, 92:1-19. DOI: 10.1016/S01678809( 01 ) 00286-9.

[36] Codification Committee of Ninglang Record ed. Ninglang record. Kunming: Yunnan Nationalities Publishing House, 1991. [宁蒗县志编撰委员会. 宁蒗彝族自治县志. 昆明: 云南民族出版社, 1991. ]

[37] Chen Chuanhong. Algal records in sediment of Lugu Lake and its response to climate change over the last 200 years [Dissertation]. Wuhan: Central China Normal University, 2012. [陈传红. 近 200 年泸沽湖藻类沉积记录及其对气候变化 的响应 [学位论文]. 武汉: 华中师范大学, 2012.]

[38] Wu D, Zhou AF, Liu JB et al. Changing intensity of human activity over the last 2,000 years recorded by the magnetic characteristics of sediments from Xingyun Lake, Yunnan, China. Journal of Paleolimnology, 2014, 53(1) : 47-60. DOI: 10.1007/s10933-014-9806-2.

[39] Gong ZJ, Li YL, Shen J et al. Diatom community succession in the recent history of a eutrophic Yunnan Plateau lake, Lake Dianchi, in subtropical China. Limnology, 2009, 10(3) : 247-253. DOI:10.1007/s10201-009-0282-8.

[40] Liu G, Liu Z, Gu B et al. How important are trophic state, macrophyte and fish population effects on cladoceran community? A study in Lake Erhai. Hydrobiologia, 2014, 736( 1) : 189-204. DOI:10.1007/s10750-014-1906-5.

[41] Xu H, Liu XY, An ZS et al. Spatial pattern of modern sedimentation rate of Qinghai Lake and a preliminary estimate of the sediment flux. Chinese Sci Bull, 2010, 55(Z1) : 384-390. DOI:10.1007/s11434-009-0580-x.

[42] Li Heng, Xu Tingzhi. The geobotanical expedition on Lake Lugu. Acta Botanica Yunnan, 1979, 1(1): 125-137. [ 李恒, 徐廷志. 沾沽湖植被考察. 植物分类与资源学报, 1979, 1(1): 125-137.]

[43] Zhu Jinge, Hu Weiping, Hu Chunhua. Distribution of deposition rate of Lake Taihu and its health assessment. Resources and environment in Yangtze Valley, 2010, 19(6): 703-706. [ 朱金格, 胡维平, 胡春华. 太湖沉积速率分布演化及其 淤积程度健康评价. 长江流域资源与环境, 2010, 19(6): 703-706.] 